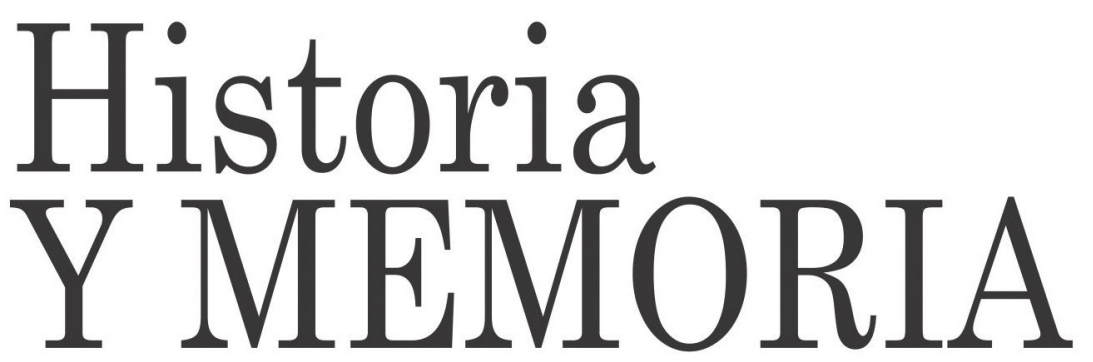

Comer en Nueva España. Privilegios y pesares de la sociedad en el siglo XVIII

Enriqueta Quiróz Páginas: 19 - 58 


\title{
Comer en Nueva España. Privilegios y pesares de la sociedad en el siglo XVIII*
}

\author{
Enriqueta Quiróz ${ }^{1}$ \\ Instituto de Investigaciones \\ Dr. José María Luis Mora-México
}

Recepción: 29/11/2013

Evaluación: 01/12/2013

Aceptación: 25/02/2014

Artículo de Investigación e Innovación.

\section{Resumen}

El propósito del artículo es entregar una visión de las prácticas alimentarias cotidianas de los habitantes del virreinato de la Nueva España durante el siglo XVIII, bajo una perspectiva de larga duración que permite la comprensión de una dinámica de cambios en las costumbres, relacionadas con la convivencia y el aprovechamiento del privilegiado entorno natural novohispano. Las prácticas alimentarias son utilizadas además, para detectar distinciones sociales en el comer, que no estarían necesariamente relacionadas con la procedencia étnica de

\footnotetext{
* Este artículo es producto del proyecto de investigación titulado: Trabajo y consumo en ciudad de México en el siglo XVIII, financiado por el Instituto de Investigaciones Dr. José María Luis Mora, México.

${ }^{1}$ Doctora en Historia, Instituto de Investigaciones Dr. José María Luis Mora. Grupo de investigación: Seminario de Pensamiento Económico. Instituto de Investigaciones Históricas UNAM. Seminario de Ciudad de México. I. Mora. Líneas de investigación: Abasto, consumo de alimentos y condiciones de vida en el pasado colonial hispanoamericano.equiroz@mora.edu.mx.
} 
la población, sino más bien con los costos de los alimentos y las posibilidades de adquirirlos. En ese sentido, se distinguen consumos de sectores privilegiados, de grupos de trabajadores y de miserables e indígenas.

Palabras clave: alimentos, costumbres, privilegios, vida cotidiana, trabajadores, recetarios, raciones.

\title{
Eating in New Spain, privileges and regrets of society in the XVIII century
}

\begin{abstract}
This paper aims at demonstrating the daily eating habits of the inhabitants of the Viceroyalty of New Spain during the XVIII century. This study seeks to understand the dynamic changes in habits related to coexistence, and the exploitation of the privileged setting of New Spain, from a long term perspective. Eating habits are used to identify social distinctions inherent in eating, which are not directly related to the ethnic background of the population, but to the cost of food and the possibility of obtaining it. Hence, the consumption of privileged sectors, workers, people in extreme poverty and indigenous groups can be identified.
\end{abstract}

Key words: Food, habits, privileges, daily life, workers, cookbooks, portions.

\section{Manger en Nouvelle Espagne. Privilèges et malheurs de la société au XVIII' ${ }^{\mathrm{e}}$ siècle}

\section{Résumé}

Le but de cet article est de donner un aperçu des pratiques alimentaires quotidiennes des habitants de la vice-royauté 
de Nouvelle Espagne durant le XVIII ${ }^{\mathrm{e}}$ siècle, selon une perspective de longue durée permettant la compréhension de la dynamique de changements dans les coutumes, liées à la cohabitation et l'utilisation de l'environnement naturel particulier de ce royaume. L'étude des pratiques alimentaires est utilisée, en outre, pour détecter, dans le fait de manger, des distinctions sociales qui ne seraient pas nécessairement liées à la provenance ethnique de la population, mais plutôt aux prix des aliments et aux possibilités de les acquérir. En ce sens, nous distinguons un type particulier de consommation de secteurs privilégiés, par rapport à celui des groupes de travailleurs, des pauvres et des indigènes.

Mots clés: Aliments, Coutumes, Privilèges, Vie quotidienne, Travailleurs, Livres de cuisine.

\section{Introducción.}

El presente artículo intenta dar una visión de las prácticas alimentarias cotidianas de la sociedad novohispana durante el siglo XVIII y de sus distinciones sociales en el comer, que no estarían necesariamente relacionadas con la procedencia étnica de las personas. Una sociedad fuertemente mestizada como la novohispana en el siglo XVIII, habría propiciado que los grupos privilegiados, especialmente de los centros urbanos, crearan diferenciaciones en el comer relacionadas con el costo de los alimentos y su accesibilidad para adquirirlos. Al grado de crear una comida de lujo y otra diferenciada para los pobres, directamente relacionada con el ahorro dentro de una racionalidad perfectamente justificada por el pensamiento ilustrado. La metodología empleada tiene sus bases en la Historia Material y la Historia de la Vida Cotidiana; para ello se recogieron fuentes manuscritas e impresas, a través de las cuales se intentó recrear la lenta dinámica de cambios en las costumbres culturales, 
relacionadas con la convivencia y el conocimiento mismo del entorno natural. Lo que también se relacionó con el conocimiento en la época sobre la salud, el estímulo de conservar la vida y proveerse el sustento diario.

\section{Los privilegios: la fertilidad del suelo, granos, carnes y frutas, lo dulce, los estimulantes y los condimentos.}

Los viajeros y cronistas españoles que llegaron a la Nueva España, no dejaron de alabar la riqueza natural de estas tierras, donde los frutos de los árboles, tan abundantes y variados, eran un regalo para ricos y pobres. Estos comentarios, no sólo fueron producto de la fascinación inicial por el nuevo mundo "descubierto" en el siglo XVI, sino que esta percepción continuó en los siglos posteriores; Fray Francisco de Ajofrín, recorrió el territorio novohispano durante el año 1763, y no dejó de reparar en la abundancia de los frutos regionales, la fertilidad de las semillas y la multiplicidad de huertos y granjas que encontraba a su paso, tanto por tierras "frías y calientes". A simple vista, parecía que en la Nueva España, no había que prever la forma de alimentarse, al menos de un modo tan riguroso como en Europa. ${ }^{2}$

La fertilidad de las tierras novohispanas es un tema que fue tratado seriamente por los sabios de fines de la época colonial, entre ellos Abad y Queipo, y el más conocido Alejandro de Humboldt, para quién la productividad del trigo era superior cinco o seis veces la de Francia. Calculó como producto medio entre 22 y 25 granos por uno en diversas haciendas, siendo las más generosas las de Cholula (Puebla), en Atlixco y Celaya, gran parte

${ }^{2}$ Francisco de Ajofrin, Diario del viaje a la Nueva España (México: Secretaría de Educación Pública, 1986), 177 y 154. 
del Bajío y también en los obispados de Michoacán y Guadalajara donde su producto era de 22 a 30 por uno. ${ }^{3}$ Dichas observaciones no eran puro optimismo si las confrontamos con los estudios de Van Bath para la Europa del siglo XVIII, donde la productividad de las zonas más fértiles localizadas en Francia e Inglaterra, demuestran un rendimiento de la simiente de 1 a 3 como mínimo y de 1 a 10 como máximo, y de 1 a 9 y 1 a 12 , respectivamente; con lo que la Nueva España aparece como una región verdaderamente privilegiada. ${ }^{4}$

Por su parte, el maíz mucho más productivo que el trigo, se adaptaba a cualquier tipo de suelo y a las diferencias de humedad, pudiendo cultivarse en todas las tierras del virreinato. Padecía con las heladas, pero se recuperaba fácilmente y también de las grandes sequías. En los meses de lluvia, podía captar suficiente agua para reponerse -según Humboldt- la anchura de sus hojas era la que contribuía mucho a la nutrición y fuerza vegetativa de la gramínea. ${ }^{5}$ En algunas zonas del Valle de México, como por ejemplo en Chalco, se sembraba hasta en tres épocas distintas del año. Aunque en general la cosecha de maíz era muy favorable en todo el mencionado Valle y sus alrededores, produciendo frutos en un promedio de seis meses. El rendimiento calculado en el siglo XVIII, de acuerdo a la cantidad sembrada y la cantidad cosechada, alcanzaba proporciones habituales de 1 a 100 y de 1 a 200 granos, aunque podían tener rendimientos extraordinarios de 1 a 300 e incluso de 1 a $800 .{ }^{6}$

\footnotetext{
${ }^{3}$ Alejandro Humboldt, Ensayo Político sobre el reino de la Nueva España (México: Porrúa, 1978), 257-258.

4 Slicher Van Bath, Historia agraria de Europa Occidental, 500-1850. (Barcelona: Península, 1974), Véase Apéndice, tabla III.

${ }^{5}$ Alejandro Humboldt, Ensayo Político sobre el reino de la Nueva España (México: Porrúa, 1978), 257.

${ }^{6}$ Charles Gibson, Los aztecas bajo el dominio español (México: Siglo XXI Editores, 1967) 317 y 335-336.
} 
Para validar estos datos de fertilidad, se les puede confrontar con cifras de abasto de las principales ciudades del virreinato durante el siglo XVIII; los volúmenes de ingreso de trigo a Zacatecas fluctuaron entre 3 y 10 mil cargas anuales de harina; a Guadalajara entre 10 y 16 mil cargas de trigo y harina durante los años de mayor demanda; a Querétaro casi 14 mil cargas anuales; a Puebla más de 63 mil cargas en 1801 y a Ciudad de México, la ciudad de mayor demanda de alimentos del virreinato, entre $100 \mathrm{y}$ 120 mil cargas anuales de harina de trigo. ${ }^{7}$ Además de los volúmenes de harina, también se contaba con los de maíz: a Zacatecas ingresaron entre 10 mil cargas y 20 mil cargas anuales durante el siglo XVIII, a Guadalajara entre 15 mil y 26 mil cargas anuales y a Ciudad de México entre 20 y 60 mil cargas de maíz. ${ }^{8}$ Es decir, al parecer existió un flujo normal de granos hacia las ciudades y sus niveles de abasto se adaptaron a los crecimientos demográficos, salvo en años excepcionales, como el año 1785, como se verá más adelante.

Los mercados repartidos a lo largo del territorio impresionaban a los viajeros por el surtido y abundancia

\footnotetext{
7 José Manuel Martín Ornelas, "La organización económica regional y el abasto urbano: el trigo y el maíz en Zacatecas, 1749-1821" (Tesis para optar al grado de Doctor en Historia. Universidad Autónoma de Zacatecas; 2008), 280; Eric Van Young, La ciudad y el campo en el México del siglo XVIII (México: Fondo de Cultura Económica, 1989) 72; John Super, "Pan, alimentación y política en Querétaro en la última década del siglo XVIII", Revista Historia Mexicana 30: No. 2 (1980): 247 y 250; Clara Suárez, La política cerealera y la economía novohispana: el caso del trigo (México: Colección Miguel Othón de Mendizábal, CIESAS, 1985) 133.

8 José Manuel Martín Ornelas, "La organización económica regional y el abasto urbano: el trigo y el maíz en Zacatecas, 1749-1821" (Tesis para optar al grado de Doctor en Historia. Universidad Autónoma de Zacatecas; 2008) 176; Eric Van Young, La ciudad y el campo en el México del siglo XVIII (México: Fondo de Cultura Económica, 1989) 89-90; Fabián de Fonseca y Carlos de Urrutia, Historia General de la Real Hacienda (México: Imprenta de Vicente García Torres, 1853); Enrique Florescano, Fuentes para la historia de la crisis agrícola de 1785-1786 (México: Archivo General de la Nación, 1981) 192.
} 
de comida, aunque el más surtido del virreinato era sin duda el de Ciudad de México. Hernán Cortés, describió en el siglo XVI la zona de Tlatelolco y en el siglo XVII y XVIII, viajeros como Giovanni Gemelli Careri y Juan de Viera, atestiguaron sobre el mercado del Volador y muchas otras plazas, en las que la gente podía encontrar todo el año hortalizas y frutas de toda especie. Esto se debía en gran parte a las chinampas, verdaderos huertos flotantes de origen prehispánico, que en el siglo XVIII pervivían hacia el sur de la ciudad. José María Alzate señaló, lo mismo que los estudiosos de hoy ratifican, que en el suelo de las chinampas se cultivaba en una secuencia cíclica, una asociación diversa de plantas, con tiempos de maduración distintos. La producción intensiva de hortalizas, una agricultura independiente del régimen de lluvias y una condición acuática, que beneficiaba el transporte de los cultivos, garantizó el abasto permanente de hortalizas a los habitantes de Ciudad de México. ${ }^{9}$

Junto a estos antecedentes y a la adaptación completa de las plantas traídas por los españoles, podemos intuir que la dieta novohispana estaba compuesta por una variedad de especies autóctonas y foráneas. En la tierra caliente y zonas del golfo de México, se decía que los limones se cogían por los caminos y se preparaba agua endulzada con azúcar de los trapiches y había montes llenos de plátanos. Hacia Oaxaca y el Bajío, había peras, granadas, membrillos, nueces, manzanas, uvas, junto a otros frutos "peculiares" del país, como guayabas, chirimoyas, tejocotes, mangos, etc. $^{10}$

\footnotetext{
${ }^{9}$ Consúltese José Antonio Alzate y Ramírez, Gaceta de Literatura de México, (Puebla: Manuel Buen Abad,1831) Tomo II, 382-397, mismo que ha sido confirmado por investigaciones posteriores, Charles Gibson, Los aztecas bajo el dominio español (México: Siglo XXI Editores, 1967) y más recientemente por Teresa Rojas Rabiela, La agricultura chinampera. Compilación Histórica (México: Universidad Autónoma de Chapingo, 1983).

${ }^{10}$ Francisco de Ajofrin, Diario del viaje a la Nueva España,...133.
} 
Estos relatos de viajeros europeos parecen exagerados, pero responden al asombro de quienes veían alterado su imaginario tradicional; en Nueva España "cualquiera" podía coger frutos, que en Europa -diría Massimo Montanari- sólo eran privativos de los nobles, como los que crecían despegados del suelo, los más coloridos y dulces, ya que sólo las raíces, los bulbos y plantas rastreras servían de alimento para los campesinos. Ideas que finalmente reflejaban el imaginario estamental de la sociedad de antiguo régimen, pero que en el nuevo mundo parecían relativos. Evidentemente, en un suelo rico y pródigo durante todo el año, no bastaba con servirse exquisitas frutas para distinguirse del resto, como pudo ser en otras latitudes donde el invierno impedía la abundancia de hortalizas y otros vegetales.

En Nueva España la cocina no estaba determinada por las estaciones del año como era en el Viejo Mundo, tal como tradicionalmente lo había expresado Domingo Hernández, cocinero del Colegio Mayor de Oviedo en Salamanca. ${ }^{11}$ En su recetario diferenciaba las comidas de invierno y de verano, y se dejaba en evidencia que el frío, apenas permitía a los nobles españoles comer ensaladas de escarola, con aderezo de aceite, vinagre y pimienta y sólo, el calor del verano los premiaba con antes o principios de guindas, uvas, melones e higos. Muy diferente, era la estructura de los libros de cocina novohispana, donde el modo de preparación, el orden de servirlos y los sabores primaban como criterio de exposición de múltiples platillos inventariados a lo largo del tiempo; las primeras recopilaciones fueron de Sor Juana en el siglo XVII,

${ }^{11}$ Hernández y Maceras. El libro del arte de cozina: en el qual fe contiene el modo de guifar de comer en qualquier tiempo... (Compuesto por Domingo Hernández de Maceras, cozinero en el Collegio mayor de Oviedo de la ciudad de Salamanca, 1607) 
posteriormente en el XVIII aparecieron por ejemplo el recetario de Dominga de Guzmán, entre otros. ${ }^{12}$

La criolla Dominga, permite percatarnos de cómo aquella pródiga naturaleza invitaba a desplegar la creatividad culinaria para convertir en un lujo, lo que estaba al alcance de la mano, como por ejemplo preparar mermeladas y dulces de frutas nativas como el zapote, el tejocote piña o coco. También licores y aguas de frutas, ya que no bastaba el agua sola, sino que se le agregaba el sabor de alguna fruta, siendo el más sofisticado saber de los conventos las aguas frescas con el sabor de guindas, de rosas, de limón, horchata, agua arzobispal, agua divina, agraz, de hipericón, de anís, etc. ${ }^{13}$ La cocina del siglo XVIII, enseñaba que la manera de preservar el perfume de las frutas y sus delicados colores, era cristalizarlas con piloncillo o azúcar negro, que molido y derretido, servía para envolverlas. ${ }^{14}$ De ello sabían especialmente las monjas, que con arte y esmero, hacían los dulces más atractivos y llamativos de las fiestas de los Santos Patrones, distinguiéndose sus confites de azúcar en los mercados. $^{15}$

${ }^{12}$ Véase Elisa Vargas, Recetario novohispano: México, siglo XVIII (México: Consejo Nacional para la Cultura y las Artes, 2000), Dominga de Guzmán, Recetario Mexiquense. Colección de recetarios antiguos (México: Consejo Nacional para la Cultura y las Artes, 1999) y el Recetario de Fray Jerónimo de San Pelayo en Archivo de la Biblioteca Nacional, (ABN), Fondo Reservado/ Archivo Franciscano/ ms. 1679.

${ }^{13}$ Véase Artemio Valle Arizpe, Por la vieja calzada de Tlacopan (México: Compañía General de Ediciones, 1954), 105; Salvador Novo, Cocina mexicana o historia gastronómica de la ciudad de México (México: Estudio Salvador Novo, A.C., 1993), 58.

${ }^{14}$ Sonia Corcuera, Entre gula y templanza (México: Universidad Nacional Autónoma de México, 1981), 102-103.

${ }^{15}$ Véase Artemio Valle Arizpe, Por la vieja calzada de Tlacopan (México: Compañía General de Ediciones, 1954), 104-105. Véase también Salvador Novo, Cocina mexicana o historia gastronómica de la ciudad de México (México: Estudio Salvador Novo, A.C., 1993), 25. 
La mezcla de azúcar y harinas, llegó a la máxima expresión no sólo por la abundancia de ambos ingredientes en el territorio, sino por la sofisticación que alcanzaron sus preparaciones. El Recetario novohispano del siglo XVIII detallaba una veintena de modos de preparar buñuelos, masas para pasteles finos, pastelillos y bizcochos. Así también en el Recetario de Dominga de Guzmán, se detallan otras tantas maneras de preparar bizcochos con queso, almendras, avellanas, chocolate, naranja, limón, castañas, etc.

El llamado pan salado, que también era un hábito alimentario, especialmente en las ciudades, donde se distribuía con normalidad en colegios, hospitales y hospicios, incluso en las grandes casas de la sociedad, se repartía como ración obligada entre los sirvientes. Las distinciones sociales estaban no sólo en las cantidades, sino en lo refinado de sus ingredientes. En Ciudad de México los panes eran de hogazas de más de 600 gramos cuando eran de "pan común" y un poco más pequeñas si eran de "pan floreado", es decir, los que se hacían de harina blanca y refinada; también existía el pan especial (de tipo francés, español y floreado especial), el panbazo y el semita, hechos de esquilmos de harina, trigos averiados y salvado. ${ }^{16} \mathrm{El}$ refinamiento de los panes se pagaba con una menor cantidad recibida, es decir, mientras descendía la calidad de los panes, aumentaba el peso por unidad, así que los panes más caros eran los más livianos y viceversa; en consecuencia los consumidores compraron durante todo el siglo XVIII, más gramos de pan común que de floreado por una moneda de medio real. ${ }^{17}$

\footnotetext{
16 Virginia García, Las panaderías, sus dueños y sus trabajadores. Ciudad de México, siglo XVIII (México: Ediciones Casa Chata No. 24, CIESAS, 1989), 158-159.

17 Véase Gazetas de México (México: Felipe de Zúñiga y Ontiveros, 1786) t. II, 9, 169, 199 y también Archivo Histórico del Distrito Federal (AHDF), Real Audiencia Fiel Ejecutoría/ Panaderías/vol.3827/ exp.107 y Enriqueta Quiroz, "La moneda menuda en la circulación monetaria de la ciudad de México. Siglo XVIII". Revista Mexican Studies/Estudios Mexicanos 22, No. 2 (Summer, 2006): 220.
} 
De manera similar en Jalapa (Veracruz) las calidades de pan se agrupaban en tres grandes categorías, como eran el pan blanco, el francés y el semita, con un consumo diario por persona de 500 a 700 gramos. En Guadalajara, los panes se clasificaban en pan blanco y de segunda clase, que era el pan de los pobres. En Querétaro, al igual que la capital, había aún mayor diversidad de panes salados, los que se diferenciaban por el refinamiento y cernido de la harina; los panaderos por reglamento estaban obligados a vender pan floreado y pan común en piezas de 20 1/2 y 25 onzas (aprox.500 y 600 gramos respectivamente), pero además vendían pan francés, de manteca, panbazo y pan sobado. ${ }^{18}$

Entre masas y harinas, el nixtamal, era la masa más común, se preparaba de granos secos de maíz que se ponían a cocer en agua y cal y se dejaban reposar hasta el día siguiente; entonces se los lavaba y se procedía a molerlos en el metate, agregando agua hasta conseguir una masa suave y uniforme. Con ella se preparaban tamales y tortillas, alimentos que acompañaban desde el desayuno hasta la cena; su cocción rápida sobre el comal facilitaba darle formas diversas según las necesidades requeridas, también, permitía contar con un pan, que siempre se comía fresco y caliente, abundante y masivamente. Del mismo modo, la harina de maíz servía para preparar bebidas matutinas como el atole: "maíz molido y colado y hecho del modo de la poleada, que queda más blanco que la almendra molida" que era regular alimento de la gente pobre y desvalida, incluso su consumo era aconsejado para los enfermos pues no

18 Guy Rozat, "Modelos para el consumo de pan en Xalapa a fines de la colonia" en Población y Estructura Urbana en México, siglos XVIII y XIX, (Xalapa: Universidad Veracruzana, 1996), 204 y 207. Eric Van Young, La ciudad y el campo en el México del siglo XVIII (México: Fondo de Cultura Económica, 1989), 74. John Super, "Pan, alimentación y política en Querétaro en la última década del siglo XVIII", Revista Historia Mexicana 30: No. 2 (1980) 254, 256. 
irritaba los intestinos y evitaba la fatiga. ${ }^{19}$ También servía de refresco y sustento de los viajeros, en su presentación de pozol: "bebida de indios, compuesta de cacao y maíz con algunos otros ingredientes de que hacen una masa blanca que beben desleída en agua fría o caliente y tiene un agrito no despreciable". ${ }^{20}$ Es decir, el maíz se consumía dulce o salado y mezclado con diversos ingredientes; el tamal es el mejor ejemplo, ya que se podían rellenar tal como lo hizo notar Juan de Viera, con carne de cerdo, chile, camarón, pescado o con dulces de frutas.

Sin duda fue una gran innovación, dentro de lo que había sido la dieta tradicional prehispánica, mezclar el maíz con grasa de cerdo; antes de la conquista los indígenas no usaban grasa en la preparación de los alimentos y no los freían. La manteca fue introducida por los españoles, adoptada por los criollos y mestizos, y finalmente asimilada por los nativos, los que la incorporaron como ingrediente que daba sabor a sus alimentos y no necesariamente como medio de cocción, así la grasa pasó a incorporarse a los frijoles, al pozole y a la masa de los tamales. Además del gusto por el sabor grasoso, en la época se buscaba dar consistencia o densidad a las comidas, especialmente a los caldos de carne, se les agregaba un cuarto de gallina, cuya piel y grasa natural daba fortaleza a los enfermos, con el mismo afán se utilizaba el tocino: "conveniente poner en las ollas o marmitas, algunas porciones de [éste] con que se disimule la flaqueza que se experimenta en los caldos". ${ }^{21}$ Los caldos eran de carne de carnero o res, combinada con gallina. La que otorgaba particular sabor a la res, más

\footnotetext{
19 Juan de Viera, Compendiosa narración de la ciudad de México (México: Guarania, 1952), 212.

${ }^{20}$ Fray Francisco Ajofrin, Diario del viaje a la Nueva España,... 170.

${ }^{21}$ Véase "Reglamento de hospitales para 1739, tanto para empleados como para enfermos convalecientes o "de poco cuidado"'. Archivo General de la Nación (AGN)/ Hospitales/ vol. 16/ exp. 3 y 5/1739.
} 
insípida y con menos grasa, que la carne de carnero. Para José Antonio de Alzate, el carnero era más saludable precisamente por su alto contenido de grasas, idea que se refrenda con dietas de hospitales donde se recomendaba a los enfermos y sólo si no se disponía de carnero, se les podía dar res. Dichos "vigorosos" caldos se recetaban por ejemplo en el hospital de San Lázaro, donde el "puchero de carnero" y otros platillos de la misma carne, se servían en la comida y la cena; por su parte, Dominga de Guzmán no dejó de incluir en su recetario algunos pucheros de fácil digestión para enfermos y convalecientes con base en carne de borrego. La grasa también servía de conservante natural. La carne fresca vendida en las tablajerías, obligaba con urgencia a prepararla y sazonarla para conservarla en los hogares. En ese sentido, lo más sencillo era salarla, engrasarla y tasajearla, es decir, preparar carne en cecina o acecinada, también adobada si se le incorporaba chile. ${ }^{22}$

En los pueblos la gente más humilde hacía sus reservas de dinero y compraba con la paga del día sábado sus raciones de carne:

Los pobres que viven en los pueblos donde se vende carne economizan todo lo que pueden, hasta el sábado en la noche que vienen de su trabajo, a fin de poder comprar medio o un real de carne fresca para comerla el domingo. Algunos compran de una vez buena cantidad, y la hacen tasajos, que son pedazos de carne arrollada y atada fuertemente. ${ }^{23}$

Hacia el siglo XVIII comer carne en ciudad de México, era un hábito cotidiano y las raciones parecían

${ }^{22}$ Enriqueta Quiroz, Entre el lujo y la subsistencia. Mercado, abastecimiento y precios de la carne en la ciudad de México, 1750-1812 (México: El Colegio de México/Instituto Mora, 2005), 85.

${ }_{23}$ Thomas Gage, Nuevo reconocimiento de las Indias Orientales (México: Consejo Nacional para la Cultura y las Artes, 1994), 84. 
más generosas que en Europa en el mismo siglo. Sin duda, hubo diferencias notables en las raciones diferenciadas socialmente, en los grupos acomodados de Ciudad de México era habitual comer unos 460 gramos diarios, repartidos dos veces al día y los indios que apenas comían "su maíz, su chile, alguna panocha y alguna carne de toro", la ración de carne debió fluctuar en unos 160 gramos diarios. ${ }^{24}$

El consumo de carne de res, carnero y cerdo, existió abundantemente en el virreinato. En el siglo XVIII a Ciudad de México entraban anualmente entre 15 mil y 30 mil reses, unas $250 \mathrm{mil}$ a $300 \mathrm{mil}$ cabezas de carneros, además de 50 mil cerdos anualmente, para surtir una ciudad de casi 120 mil habitantes. Por su parte, en Guadalajara, se sacrificaban anualmente entre 3 mil y 5 mil reses y unos 3 mil y 8 mil borregos para una población de 64 mil habitantes en 1793. Así también en Valladolid (Michoacán), se sacrificaban alrededor de 1800 reses y entre 5 mil y 8 mil carneros, para surtir a 17 mil personas ese mismo año y en Cuernavaca se ha estimado que se requerían unas 4000 reses para abastecer a unas 40800 personas. ${ }^{25}$

El ayuntamiento de la Ciudad de México con la venta de carne de res y carnero pretendía garantizar el consumo de carne a dos grupos extremos de la sociedad: "consistía en carnero y toros, usando los ricos de la carne de los primeros, y los pobres de la de los segundos”. A

\footnotetext{
${ }^{24}$ Enriqueta Quiroz, Entre el lujo y la subsistencia. Mercado, abastecimiento y precios de la carne en la ciudad de México, 1750-1812 (México: El Colegio de México/Instituto Mora, 2005), 80.

${ }^{25}$ Enriqueta Quiroz, Entre el lujo y la subsistencia... 109-110; Eric Van Young, La ciudad y el campo en el México... 57; Fernando Soria, "Ganaderos, precios y abasto de carne en Valladolid de Michoacán, 1778-1813" (Tesis Pregrado, Universidad Michoacana de San Nicolás de Hidalgo, 2009), 80; Ward Barrett. "El abasto de carne en Cuernavaca durante la época colonial", en Consumo e Historia. Una Antología (México: Instituto Mora, 2009), 202.
} 
medida que se descendía en la escala social la carne de res se trasformaba en "la carne" de los más necesitados y se remataba el abasto de res y carnero a quienes ofrecieran los precios más bajos, siempre aceptando que el carnero fuese más caro que la res. ${ }^{26}$ Por su parte, la carne de cerdo se usaba en la comida de todos los grupos sociales, con la selección de partes que iban desde la sangre, la grasa, la piel y las vísceras.

Los guisados de carne en general, no siempre eran de grandes trozos sino simplemente "picadillos de carne", bofes, sesos, manitas, cabezas, menudo, morcilla, chorizo, jamón, etc., todos se preparaban con variedad de hortalizas, habiendo combinaciones corrientes como la de jitomate, chile ancho, cebollas. También otras más sofisticadas, con ajo, aceitunas y alcaparras, en preparaciones más complejas donde las carnes se estofaban, se enrollaban, se amoldaban o se cocían con infinidad de ingredientes como el plátano, el camote, la piña, la manzana, la pera y el betabel para dar sazones agridulces a los guisados. ${ }^{27}$

Sólo por lujo, las carnes se rellenaban o mezclaban con frutos secos, tales como las nueces, los piñones, las almendras, las pasas y el ajonjolí tostado; se aderezaban con azafrán, clavo, pimienta, canela, perejil, acitrón, chiles verdes, chiles anchos, tornachiles. Los guisados más sofisticados eran agridulces, consistentes, grasosos y coloridos, en ellos todo se mezclaba y se disfrutaba como un conjunto indisoluble de sabores y aromas.

\footnotetext{
${ }^{26}$ Enriqueta Quiroz, Entre el lujo y la subsistencia... 101-103, véase la reconstrucción que hizo la autora de los precios de la carne de res y de carnero entre 1701-1811.

${ }^{27}$ Véase Dominga de Guzmán, Recetario Mexiquense. Colección de recetarios antiguos (México: Consejo Nacional para la Cultura y las Artes, 1999) y también Elisa Vargas, Recetario novohispano: México, siglo XVIII (México: Consejo Nacional para la Cultura y las Artes, 2000).
} 
Massimo Montanari nos ha hecho ver que en Europa las especias -luego del siglo XVI cuando su uso se hizo generalizado- habrían provocado cierto cansancio en la población y la cocina se inclinó por lo graso y aromas más delicados. ${ }^{28}$ No obstante en la Nueva España del siglo XVIII, pervivía ese gusto por condimentar generosamente las comidas, tal como si existiese en la alta sociedad un afán por disfrutar sensaciones variadas al comer. En ese sentido, algunos viajeros calificaron su dieta como epicúrea, según Thomas Gage en la Nueva España, existía una sazón muy elaborada, propia de una sociedad entregada a los placeres, así el viajero indicaba: “(...) se lo he oído a los españoles confesarlo, que la España ha aprendido de las Indias muchas lecciones para el aliño de varios manjares y para hacer completa una fiesta o un banquete". ${ }^{29}$

Era comida que explotaba el sabor dulce, salado, agrio y picante, es decir, ampliaba la dualidad tradicional dulce/ salado de occidente; también explotaba ciertos perfumes de frutos introducidos, como el jazmín, limón, naranja, anís, jengibre, azafrán, la nuez moscada y ajonjolí; sin olvidar lo cotidiano de la cebolla, el perejil y el ajo de los españoles, como también el clavo, la pimienta, la canela, el comino, el orégano y la yerbabuena. ${ }^{30}$ Costumbre que se diferenciaba de la natural disposición de los indígenas, para agregar sabor a sus alimentos a través de muchos tipos de chiles que decían, despertaban el apetito y ayudaban a la digestión. ${ }^{31}$

\footnotetext{
${ }^{28}$ Massimo Montanari, El hambre y la abundancia: historia y cultura de la alimentación en Europa (Barcelona: Crítica. Grupo Grijalbo, 1993), 119.

29 Thomas Gage, Nuevo reconocimiento de las Indias Orientales (México: Consejo Nacional para la Cultura y las Artes, 1994), 271.

${ }^{30}$ Salvador Novo, Cocina mexicana o historia gastronómica de la ciudad de México (México: Estudio Salvador Novo, A.C., 1993), 63.

${ }^{31}$ Francesco Carletti, Razonamiento de mi viaje alrededor del mundo (1594-1606) (México: Universidad Nacional Autónoma de México -Instituto de Investigaciones Bibliográficas, 1976) 72 y Fray Francisco Ajofrin, Diario del viaje a la Nueva España (México: Secretaría de Educación Pública, 1986), 162, 175.
} 
Fuera del ámbito de la salud, lo más lujoso era combinar sabores y sorprender a los comensales, al extremo de producir la fusión más compleja y rara. Tal como se dio en el platillo, que hoy día es el más típico de la cocina mexicana, el mole. Se dice que fue creado por monjas poblanas en el siglo XVII para satisfacer el paladar de un virrey. El mole originalmente se preparó con guajolote o pavo, variedad de chiles, entre ellos pasilla, chipotle ancho y mulato, los que se tostaban y molían junto a granos de cacao, cacahuate, almendra, nueces, pasitas, canela, anís, además de manteca y ajonjolí. Aunque sin duda su ingrediente más atractivo, era el cacao o chocolate, que al parecer estaba presente en el quehacer cotidiano de las cocinas del virreinato.

El cacao se hizo tan popular, que hasta se debatió su consumo porque se consideró que no era una simple bebida, sino más bien un alimento bastante complejo, del que se decía interrumpía las prácticas de ayuno religioso entrela población. Fue acuciosamente analizado por los religiosos y sabios del siglo XVII, quienes escribieron sobre sus componentes y efectos en las personas. ${ }^{32}$ Bajo ese análisis resultó una bebida apropiada para toda clase de estómagos, siempre y cuando no se bebiera en exceso. Se consideró que devolvía la fuerza y el equilibrio al cuerpo, incluso algunos lo bebían para estimular el trabajo nocturno y la llamada lucidez burguesa. ${ }^{33}$ Algunas personas lo bebían varias veces al día, "por la mañana, otra antes de comer entre nueve y diez, otra una hora o dos después de comer, y otra sobre las cuatro o cinco de la tarde". No había distinción social por el hecho de beberlo, aunque sí en el modo de prepararlo; los pobres lo mezclaban con maíz para darle mayor rendimiento, también con achiote, chile y

\footnotetext{
32 Antonio León Pinelo, Questión moral si el chocolate quebranta el ayuno eclesiástico. Facsímil 1603 (México: Conductores mexicanos. Centro de Estudios de Historia de México, 1994).

${ }^{33}$ Thomas Gage, Nuevo reconocimiento de las Indias Orientales... 267.
} 
algo de anís. ${ }^{34}$ Recientes investigaciones sobre los precios del cacao en la Nueva España, se inclinan por decir que era un producto barato y por lo tanto, un "fenómeno de masas", especialmente el cacao de Guayaquil que era el más barato que llegaba al virreinato; se decía que no había "negro ni peón que no [lo] tome cada día, y los más acomodados cuatro veces al día" ${ }^{35}$ Lo que marcaría una diferencia con Europa, donde se sabe que fue un consumo altamente social y también muy difundido entre los religiosos, con una imagen muy elitista, asociada a la molicie y ociosidad aristocrática.

\section{Los pesares:elcalor,lahumedadylapodredumbre; la sequía, el hambre y las enfermedades.}

En un medio de una rica biodiversidad, conseguir alimentos podría parecer sencillo y hasta natural; no obstante la población novohispana también debió enfrentar desafíos permanentes con la naturaleza. En las regiones particularmente húmedas y calurosas, el desafío era saber cocinar lo justo y necesario, sin guardar excedentes. El dominio de la naturaleza en el trópico, significaba pensar en el modo de aprovechar al máximo la pródiga naturaleza sin desperdiciar alimentos, ya que los tiempos de corrupción y putrefacción, eran veloces. En las tierras del golfo de México, los viajeros pusieron atención a este problema:

\section{[...] los alimentos se amohecen y se pudren con tanta brevedad, que de un instante a otro se pierde la carne, y así los demás comestibles, con}

\footnotetext{
${ }^{34}$ Thomas Gage, Nuevo reconocimiento de las Indias Orientales... 265 y 267.

${ }_{35}$ Manuel Miño, "El "cacao de Guayaquil" en Nueva España. Siglo XVIII". Revista Méxican Studies/Estudios Mexicanos 25, núm.1, (Winter 2009): 14-16; también Jesús Hernández Jaimes, "El fruto prohibido. El cacao de Guayaquil y el mercado novohispano, siglos XVI-XVIII". Revista Estudios de Historia Novohispana 39 (2008): 44 y 51 y Giovani Gemelli, Viaje a la Nueva España (México: Universidad Nacional Autónoma de México, Dirección General de Publicaciones, 1976), 140.
} 
lo que se hace preciso no matar más que lo que se ha de guisar inmediatamente. $\mathrm{Al}$ pan le sucede lo mismo; el chocolate se conserva tres o cuatro días, con la circunstancia de haber de estar en vasija de hojalata bien tapada [...]. ${ }^{36}$

El vivir sin guardar, también obligaba a organizar las raciones para no desperdiciarlas, saber combinar los alimentos y hacer uso sistemático de ellos, de tal modo que fuesen atractivos y saludables. Pero lo más difícil siempre fue su conservación, por eso en las zonas cercanas a montes y volcanes nevados, la gente aprovechaba su medio para conseguir nieve, no sólo para refrescar sus bebidas o degustar helados, sino para preservar sus alimentos por más tiempo. Así la nieve fue un producto escaso y caro e incluso pasó a conformar un estanco real, es decir, fue propiedad del rey y todo indígena o gañán que subiera a las montañas a recogerla pagaba un impuesto a la Real Hacienda. Por su parte conservarla siquiera por algunos días, requería crear sistemas de almacenamiento especiales, como por ejemplo las vasijas de barro cubiertas con colchonetas de plumas o embalajes especiales de paja y heno, así como neveras rusticas subterráneas. ${ }^{37}$

Otra lucha constante de la época, era lograr la conservación de los granos por largas temporadas, especialmente del trigo, que tal como lo indicó Humboldt, era más difícil que guardar cebada o centeno. En Querétaro por ejemplo, se discutía si almacenar en trojes herméticos era mejor que conservar el trigo ventilado, o incluso usar

\footnotetext{
${ }^{36}$ Francisco Ajofrin, Diario del viaje a la Nueva España... 173.

${ }^{37}$ Sobre el estanco de nieve consúltese Fabián de Fonseca y Carlos de Urrutia, Historia General de la Real Hacienda (México: Imprenta de Vicente García Torres, 1853); también Alejandro Humboldt, Ensayo Político sobre el reino de la Nueva España (México: Porrúa, 1978), 542-543 y sobre los sistemas de refrigeración de la nieve consúltese María del Carmen León García, La distinción alimentaria de Toluca (México: CIESAS, 2002) 195-201.
} 
azogue, azufre, cascudos de camarón y animales muertos, los que servían para ahuyentar gorgojos y palomillas, pero que tenían el inconveniente de destruir el poder vegetativo del grano. ${ }^{38}$ Así en Querétaro, Guadalajara y Ciudad de México, hubo quejas por emplear harina "agorgojada", "viciada", "excalentada", en definitiva harina descompuesta, a causa de su mala conservación; en esos casos los fabricantes la mezclaban con mucha grasa para disimular el mal sabor o en otros, el problema estaba en el cernido de las harinas y en el uso de calidades inferiores, mucho menos refinadas, así aumentaban el peso de los panes, como también agregándole mucha agua o levadura. ${ }^{39}$

Más bien cuando hubo escasez de granos, principalmente de maíz durante el siglo XVIII, la población del virreinato optó por la sustitución de ciertos alimentos por otros; sin embargo, la necesidad empujó a las poblaciones a adaptar sus dietas y a sobrevivir con lo que se conseguía en el momento. Las sequías azotaron al virreinato en muchas ocasiones, pero sin duda el año más perturbador del siglo fue el de 1785, llamado "el año del hambre", cuyas consecuencias se prolongaron hasta el año siguiente. Desde el mes de mayo de 1785, cuando debían comenzar a caer las primeras lluvias, se observó la sequía en los campos y sólo a fines de junio, cayó la primera lluvia, pero la situación se empeoró con las heladas repentinas de agosto y septiembre. Se sabe que el fenómeno afectó principalmente las cosechas en Guadalajara, San Luis Potosí, Guanajuato, Valladolid y Durango. También en las zonas del noroeste de la Ciudad de México, en la provincia

\footnotetext{
38 John Super, "Pan, alimentación y política en Querétaro en la última década del siglo XVIII", Revista Historia Mexicana 30: No. 2 (1980): 259.

39 John Super, "Pan, alimentación y política en Querétaro... 259; Eric Van Young, La ciudad y el campo en el México del siglo XVIII... 80; Virginia García, Las panaderías, sus dueños y sus trabajadores... 160-16.
} 
de Tehuacán, después en las provincias de los valles del centro, especialmente en el valle de Puebla y en las zonas cercanas a las cordilleras volcánicas. ${ }^{40}$

Ante la peor crisis agrícola del siglo, la gente buscó estrategias de sobrevivencia como deambular hacia las ciudades principales o hacia tierras más distantes, supuestamente no afectadas. Pese a ello, la sequía obligó a la población a buscar sustitutos alimentarios, especialmente porque los precios del maíz se vieron gravemente azotados, se sabe por ejemplo que en Ciudad de México la fanega ascendió hasta 41 reales, lo que significaba que con medio real apenas se podían comprar poco más de medio kilo de maíz, o aproximadamente 19 tortillas y media. Resulta que el maíz valía casi el doble de la carne de res, y poco menos que el carnero, ya que con un real se compraban 2 kilos de carne de res y 669 gramos de carnero. ${ }^{41}$ Fue entonces cuando la gente demostró una vez más su capacidad de adaptación fisiológica modificando sus necesidades, ya que ese no era el momento de comer mucho, sino que había que sobrevivir con poco. Aunque ante todo, operó el reemplazo de alimentos en la dieta; el arroz aderezado con chile, el pan y la carne de res sirvió de principal sustento, al igual que la diversidad de cactáceas. Los relatos de la época señalan que a los miserables se les daba "un abundante plato de arroz bien condimentado con media libra de vaca y media torta de pan"; en aquellas ocasiones en el Santuario de Guadalupe fueron "dignas de mucha atención las copiosas y diarias limosnas en arroz, tortillas, pan de semita y carne". ${ }^{42}$

\footnotetext{
${ }^{40}$ Véase, Enrique Florescano, Fuentes para la historia de la crisis agrícola de 1785-1786 (México: Archivo General de la Nación, 1981), Vol. I, 65,100101,277-278 y Arij. Ouweneel, Ciclos interrumpidos, ensayos sobre historia rural mexicana, siglos XVIII-XIX. (Zinacantepec. Estado de México: El Colegio Mexiquense, 1998), 82.

${ }^{41}$ Enriqueta Quiroz, Entre el lujo y la subsistencia... 203.

${ }^{42}$ Enrique Florescano, Fuentes para la historia de la crisis agrícola de 1785 $1786 \ldots$. 609-612.
} 
El filantropismo y el saber de los sabios ilustrados, también se puso al servicio de los grupos menesterosos. En la Gaceta de Literatura, José Antonio Alzate, científico novohispano de fines del siglo XVIII, recomendó a la población el consumo de cactáceas a causa de la escasez, tales como nopales cardones, biznagas, órganos, pitahayas, garambullos y magueyes, con lo que recogía costumbres populares y de consumo ancestral. Además se preocupó de difundir recetas europeas de bajo costo y que podían ser perfectamente preparadas en Nueva España, tal como la sopa del delfinado, preparada con pasta de harina de trigo, la sopa de arroz, la sopa de harina de trigo con verduras, a la que también se podían agregar legumbres, vísceras (corazones e hígados) y trocitos de pan. También aconsejaba, que las raciones debían ser de un cuartillo y medio de caldo y de ocho onzas de pan. La sopa debía servirse caliente porque se creía que de ese modo "satisfacía mucho más" y "fortificaba", es decir, cada vez más se aplicaban criterios racionales en la preparación de las comidas de beneficencia como la medición y el cálculo de sus costos. ${ }^{43}$

Por su parte, Wenceslao Barquera en su Semanario Económico, incluso propuso alimentar a la población hambrienta con sopas de cebada, ya que era más recomendable, que emplearla en la fabricación de pan. Su receta era cocer este cereal en agua hasta que tuviera la consistencia de una gelatina espesa y se le podían añadir otros ingredientes para darle variedad y sabor; consideraba que una ración de 20 onzas de esta sopa, con una adecuada consistencia, era bastante para alimentar a un adulto. ${ }^{44}$

\footnotetext{
${ }^{43}$ José A Alzate y Ramírez, Gacetas de Literatura de México (Puebla: Manuel Buen Abad, 1831).

${ }_{44}$ Wenceslao Barquera, Semanario Económico de México. Sobre noticias curiosas y eruditas de agricultura, medicina, minería, comercio y demás ciencias naturales, artes, oficios, literatura, etc., 1808-1810, II Vols.
} 
La iglesia dispensó a sus fieles de comer carne durante la cuaresma, particularmente los años 1786 y 1787, aunque hicieron la salvedad de conservar el ayuno los días viernes, sábado y en la semana santa. ${ }^{45}$ Por ejemplo, en San Luis Potosí se dijo que la dispensa de carne permitiría conseguir y asegurar el sustento de las familias y de los pobres, porque la carne de res permanecía barata, ya que con dos reales de esta clase de carne alcanzaba para alimentar "a 20 pobres" y por el contrario, si se compraba "pescado, lacticinios y otros comestibles de viernes" no se podría "dar de comer más que a sólo dos o tres cuando más" ${ }^{46}$ Ciertamente, no fue la primera vez que la carne, se transformaba en sustituto y sustento de la población urbana. El mismo permiso fue reiterado los años 17911792, 1794 y desde 1799 hasta $1809 .{ }^{47}$

No podemos saber si desde entonces la carne de res comenzó a ser descalificada por su dureza y mala calidad, así se la identificaba como la carne de "los pobres" y se la consideraba "poco delicada" y acaso perjudicial a la salud. ${ }^{48}$ En 1788, se denunciaba en Ciudad de México, la entrada de reses muertas, "hediondas" y descompuestas para el consumo de la población:

[...] la relación que presenta mensualmente el interventor que asiste al matadero para llevar la cuenta de las cabezas que se matan y cobrar la respectiva alcabala, consta haber meses en que se introducen 200 a 300 bueyes con la distinción de muertas y de enteramente podridas. Estas últimas

\footnotetext{
${ }_{45}$ AGN, Ayuntamientos, vol. 170, exp. 3.

${ }^{46}$ Matilde Souto, "Sobre los festines y el hambre en la Nueva España", en Gozos y sufrimientos en la historia de México (México: El Colegio de México/ Instituto Mora, 2007), 144.

47 Francisco Sedano, Noticias de México. Tomo I. (México: Imprenta de J.R. Barbedillo, 1880), 67.

48 AGN, Reales Cédulas Originales, vol. 178, exp. 41.
} 
dice distribuirse o venderse para comida de perros, pero en una población tan numerosa, desordenada y llena de infelices, no será extraño, sino muy creíble, se aprovechen de aquel alimento aunque con el riesgo de que les cueste la vida en que aventura menos el uso de carne de caballo y mula, que no en pocas ocasiones se ha hecho, hace y hará, en los bodegones y puestos de las plazas, según se ha justificado y continuará siendo inevitable, por falta de vigilancia $[. . .]^{49}$

Del mismo modo, en el año 1800 el abastecedor de carne de la Ciudad de México, Antonio Yermo, denunciaba que hasta ese momento los compradores de res, recibían "la mitad de huesos y la otra mitad en piltrafas asquerosas, que solamente pueden servir de alimento con perjuicios de la salud y detrimento de todas las facultades sensitivas a una gente miserable, y destituida de todo genero de proporciones". ${ }^{50}$

Se sabe que en la época los indígenas aminoraban la dureza de la carne, seguramente de animales viejos y musculosos, con jugo de limón, con el que la rociaban tan sólo una hora antes de cocinarla. ${ }^{51}$ Pese a todo, los restos de cabezas, de pies y de intestinos de reses y carneros, requerían una prolongada cocción y para ello se aprovechaban las largas horas de la noche; esta costumbre llegó a considerarse perniciosa por la infinidad de fogones que ardían en Ciudad de México, no sólo para preparar las carnes que se venderían en los puestos de comida al día siguiente, sino también los panes y hasta el jabón, preparado con el sebo de los animales. ${ }^{52}$

\footnotetext{
49 AHDF, Policía en general, Vol. 3627, exp. 43, 1788.

50 AHDF, Abasto de carne, vol. 7, exp. 196.

${ }^{51}$ Francisco Ajofrin, Diario del viaje a la Nueva España... 162.

${ }_{52}$ José Alzate y Ramírez, Gacetas de Literatura de México... 337-338.
} 
No sólo las enfermedades generadas en el ambiente aquejaban a la población, sino también las que eran producto de una alimentación inadecuada. Entre ellas estaban presentes por desnutrición o "descompensación alimentaria" propia de los miserables, pero también las que se originaban por exceso de comida causando trastornos digestivos. En un artículo publicado el año 1773 en el periódico El Mercurio Volante, el médico José Ignacio Barlotache, comentaba "los excesos abreviaban el número de nuestros días" y por ello aconsejaba a la gente, comer sólo lo necesario para evitar las enfermedades y la muerte. En el mismo sentido, Wenceslao Barquera señalaba en su Semanario Económico, el año 1810: "Pero qué cosa hay que no sea funesta cuando se abusa de ella", tal como lo hacían los "golosos e imprudentes" que hasta calenturas padecían por sus abusos en el comer.

Se sabe que la enfermedad de la gente acomodada era la gota, a causa del exceso de proteínas en la dieta, que junto al consumo de alcohol, se provocaba un incremento de las purinas en el organismo, lo que terminaba generando este padecimiento inflamatorio articular. En 1809 en el Semanario Económico, su autor Wenceslao Barquera, explicaba que el uso de caldos, la carne y los huevos, exponían a las personas a "enfermedades pútridas" y en cambio los vegetales las prevenían de la corrupción de las viruelas. En ese mismo sentido, Alzate acotó por ejemplo que un huevo solo debía permanecer en el agua hirviendo dos minutos y medio, para que no fuese pernicioso a la salud.

Para Barquera, los alimentos que otorgaban más años de vida eran el azúcar, el maízy las naranjas; particularmente aconsejaba a sus lectores el consumo de una libra de azúcar diaria, porque a su juicio, esa costumbre aseguraba vivir hasta los 90 o cien años. Por su parte, Alzate en la Gaceta de Literatura llamaba la atención respecto a aprovechar mejor los nutrientes de las verduras, su idea era introducir 
el hábito de cocerlas al vapor. Observaba que las verduras cocidas directamente en el agua y debido a la actividad del fuego en ella, quedaban privados de sus "partículas nutritivas", así señalaba: "esta agua por lo regular se arroja inútil, [y] el hombre tan solamente devora el esqueleto de la planta". Por este motivo los tiempos de cocción, a su juicio, no eran arbitrarios, pues de ello dependía el buen provecho o pérdida de las sustancias.

\section{Hacia una diferenciación social a partir del consumo alimentario}

Si se estudia a cabalidad el esquema alimentario de los diversos grupos de la sociedad novohispana se descubrirán diferencias distintivas entre unos y otros, tal como si ordenáramos a la sociedad por el nivel de sus posesiones materiales. En el pasado novohispano, es posible determinar a partir de los gastos domésticos, esquemas de distribución de la riqueza social. De modo tal, que los regímenes alimentarios pueden ser instrumentos útiles para identificar grupos, utilizando una base económica, pero lo más notable es que dicha herramienta no descarta el componente cultural e incluso jurídico, hasta ahora más utilizados para definir a la sociedad colonial novohispana. Por el contrario, el esquema de castas, corporaciones y estamentos, han desdeñado el componente económico para identificar a un sector social en el siglo XVIII; como si realmente no fuese parte de la comprensión del grupo en estudio y se pudiese obviar el sustrato de la riqueza entre las personas. Particularmente porque en lo que se refiere a identificar movilidad, hace necesario en los regímenes preindustriales, captar precisamente el proceso de enriquecimiento de ciertos grupos sociales. En especial, el de aquellos sectores medios que fluctuaban entre la subsistencia y el lujo. 
Este planteamiento no es nuevo, ya que por ejemplo, los estudios de Massimo Montanari para la sociedad europea de Antiguo Régimen, señalaron que el modo de comer revelaría el estado social de las personas. Basado especialmente en tratados del periodo sobre la nobleza francesa y española, el autor estableció una relación entre régimen alimentario y rango social, donde las formas de comer otorgarían la pertenencia social o incluso serían su consecuencia, servirían para destacar su rango y al mismo tiempo para reafirmarlo. El orden jerárquico de la sociedad estaba representado también en la selección que cada grupo social hacía de sus alimentos, así se establecía un paralelismo entre jerarquía de los alimentos y jerarquía de los hombres, misma que a la vez sustentaba la cultura del poder que predominaba. ${ }^{53}$

No obstante, no es tan sencillo aplicar los criterios de diferenciación social del consumo usados en Europa a los propios de América y en especial a la Nueva España. Se debe en primer lugar tener en cuenta sus propios alimentos y las particularidades regionales de la cocina tal como se hizo al comenzar el artículo. En un suelo evidentemente rico y pródigo durante todo el año, no bastaba con servirse exquisitas frutas o comer carne para diferenciarse del resto, como pudo ser en otras latitudes donde especialmente el invierno impedía el cultivo de hortalizas y determinados vegetales. En el espacio urbano, las diferenciaciones alimentarias estaban contempladas desde la organización de los abastos, bajo una concepción materialista acorde con la capacidad adquisitiva de la gente, no bajo criterios de color de piel o costumbres. En Ciudad de México y en otras ciudades de Nueva España, se fijaron precios para cuidar el bienestar y abastecimiento tanto de ricos como de pobres. A este respecto, es importante saber que las autoridades del Ayuntamiento, eran las

${ }_{53}$ Massimo Montanari, El hambre y la abundancia: historia y cultura de la alimentación en Europa (Barcelona: Crítica. Grupo Grijalbo, 1993), 91. 
que ponían particular atención respecto a la distribución de los enseres básicos entre la población porque era su obligación garantizar alimentos para todos "de acuerdo a sus posibilidades". En ese sentido, es factible estudiar para la época, la estratificación social del consumo entre los distintos cuerpos sociales, principalmente a partir de las mercancías reguladas por el abasto y vendidas en carnicerías, tocinerías, panaderías y pulperías. No era casual que hubiese distintos tipos de azúcares, distintos tipos de panes, distintos tipos de carnes, diversas calidades de maíz o de trigo, de velas, de jabón; es decir, todas las mercancías tenían como destino un hogar específico, por la calidad o cantidad expedida y en definitiva por su precio.

Pese a que la dieta de la población estaba centrada en los granos y las carnes, la utilización de un tipo en particular de éstas, o la forma de acompañarlas con ciertas hortalizas o frutas, podía indicar una diferenciación social en sus consumos. Así también la calidad y variedad de los alimentos utilizados, como la predilección por ciertas bebidas y el uso de algunos condimentos y especias, nos hacen pensar en comidas de grupos muy distintos.

Dentro delos más exclusivos rituales dela alta sociedad novohispana, figuran los banquetes de recibimiento a los virreyes, que eran meticulosamente organizados por los funcionarios reales residentes en el reino. Dichos banquetes eran la ocasión para exhibir un gran surtido de productos de lujo traídos de Europa y a la vez una oportunidad para ostentar la magnífica riqueza natural del reino. En un banquete, las carnes rojas abundaban, podían servirse varias terneras, una vaca entera, más de una docena de carneros, cochinitos de leche y cabritos. Entre las carnes blancas estaban los pavos, gallinas, pollos y aves de caza, tales como codornices, perdices, conejos, liebres, y carnes frías como jamón, tocino, chorizones y salchichas, junto al pescado blanco, bagre, las truchas, salmón y bacalao. Los 
encurtidos de España se ofrecían junto a las mantequillas y los quesos, el requesón, las pasas, las aceitunas sevillanas, los alcaparrones. También se preparaban fideos y macarrones, arroz y muy pequeñas cantidades de garbanzos y frijoles. Manojos de espárragos, docenas de alcachofas además de variedad de hortalizas. Más allá de lo salado estaba el refresco y la repostería, compuesto por el chocolate, el café, los sorbetes, también sobresalían las masas y el azúcar blanco, junto con almendras, avellanas, compotas, obleas y barquillos. ${ }^{54}$

Los selectos invitados de la sociedad, mostraban sus mejores galas, centrados en su apariencia y con mucha teatralidad exaltaban su triunfo y riqueza ante el virrey que era representante del rey en América. ${ }^{55}$ Todo era cuidadosamente preparado con meses de antelación, para lo cual el propio Ayuntamiento había destinado un presupuesto especial. La vestidura de las mesas con manteles de "algodón finamente labrado", cubiertos de plata y adornos rebuscados, como "flores de cambray, rosas de castilla, claveles, lienzos, listones, muñecos, pájaros de cera y papel picado" eran señal del copioso dinero y de las fortunas que existían en el reino. ${ }^{56}$ La idea era que los comensales admiraran la enorme cantidad de alimento, habilidosamente preparada por los mejores cocineros.

${ }_{54}$ Consúltese AGN, Correspondencia de Virreyes, primera serie, vol. 283, exp. 1, también "Cuenta presentada por los señores don A. Méndez Prieto y Fernández y Don Agustín del Rivero de los gastos que comisionados para el recibimiento del Exmo. Sr. Virrey Francisco Javier Venegas, 1810”.

55 Véase sobre el lujo de estos grupos, Artemio Valle Arizpe, Por la vieja calzada de Tlacopan (México: Compañía General de Ediciones, 1954) 88. 89 y Verónica Zárate, "Los privilegios del nombre. Los nobles novohispanos a fines de la época colonial", en Historia de la Vida Cotidiana en México. El siglo XVIII: entre tradición y cambio, vol. III (México: Fondo de Cultura Económica/El Colegio de México, 2005), 347.

${ }_{56}$ Matilde Souto, "Sobre los festines y el hambre en la Nueva España”... 139. También Cuenta y Relación jurada del recibimiento del Virrey Francisco Javier Venegas en 1810. 
Por lo general eran tres días de reunión, en lugares muy selectos en las afueras de la capital, como la Villa de Guadalupe o en San Cristóbal Ecatepec. Los tiempos eran bien marcados dentro del protocolo, "la comida, el refresco y la cena", ya que el orden era determinante dentro del ritual de presentación el que operaba como signo del poder y orden alcanzado en el propio gobierno del virreinato. La distinción de sus invitados era producto de una segmentación de la sociedad en jerarquías excluyentes, y que en definitiva propiciaba la selección de una élite, notoriamente diferente del resto de la población. Asistían a los banquetes los más altos prelados de la iglesia, los dirigentes del gobierno real y "personas de calidad" que conformaban la nobleza novohispana.

El resto de la sociedad, seguramente soñaba con reproducir aquellas magníficas fiestas atiborradas de comida, ya que sin duda la abundancia de las ricas mesas aristocráticas contrastaba con el traumático miedo al hambre del pueblo. Quizás suafán de desterrarlo, hacía que desbordaran su energía volcándose en las calles particularmente en celebraciones comunitarias, tales como las fiestas a sus santos patrones, de Corpus Cristi y o en las vísperas de Navidad o día de muertos. En dichas ocasiones, las calles se inundaban de dulces y golosinas preparadas con frutas, azúcar y chocolate, tal como si ellas fueran quizá la única, pero necesaria demostración, de la abundancia de los pobres:

El modo de solemnizar los días de los patriarcas de las religiones y el de las otras fiestas parroquiales es el de situarse a las puertas y calles de sus contornos, muchos puestos de comidas y masas como si se convidase a un gran festín profano... ¿Pues como se deberá decir ... en vista de tantos puestos de comida, de cazuelas, metates y otros instrumentos de la gula y glotonería? $[. . .]^{57}$

\footnotetext{
${ }^{57}$ Hipólito Villarroel, Enfermedades políticas (México: Porrúa, 1979), 188, 190-191.
} 
La costumbre en fiestas como el Carnaval previo a la cuaresma o durante Corpus Cristi era lanzarse comida, como si ésta realmente abundara: almendras, arvejones, cebada, anises y hasta con "papelillos de color, obleas despedazadas y listones". 58

En los días normales, especialmente en la Ciudad de México, los mercados también reflejaban la abundancia para los transeúntes, muchos atraídos desde lejos, para vender sus mercancías en la plaza mayor o en busca de escribientes o trámites por resolver, así muchos necesitaban comer, por estar lejos de su hogar. Eran verdaderos flujos cotidianos de población entrante y saliente de la ciudad, por esta razón, fue en la calle donde se recrearon las cocinas, bajo criterios de movilidad y adaptabilidad, siendo el momento de la comida tal vez el que daba cierto sentimiento de estabilidad y permanencia entre las personas que dejaban sus pueblos cotidianamente para venir a la capital virreinal. ${ }^{59}$

Si observamos dichas comidas callejeras y las de los mesones, especies de posadas, ubicados en los caminos entre pueblos y ciudades, podemos identificar marcadas diferencias sociales. No sólo por los gustos de su origen étnico, sino principalmente por el precio de las comidas, tal como lo indicó Juan de Viera en 1777, "por ser crecido el gasto de los mesones". ${ }^{60}$

${ }^{58}$ Sobre la fiesta de muertos véase Juan de Viera, Compendiosa narración de la ciudad de México (México: Guarania, 1952) 92. Sobre Navidad consúltese AGN, Hospitales, Vol. 21, fs. 40, 146, 186 y VIQUEIRA, 1987, p. 162. Sobre Corpus Cristi consúltese Artemio Valle Arizpe, Por la vieja calzada de Tlacopan (México: Compañía General de Ediciones, 1954), 86-87.

${ }^{59}$ Enriqueta Quiroz, "Del mercado a la cocina. Alimentación en la ciudad de México", en Historia de la Vida Cotidiana en México. El siglo XVIII: entre tradición y cambio, Vol. III. México: Fondo de Cultura Económica/El Colegio de México, 2005), 32-37.

60 Juan de Viera, Compendiosa narración de la ciudad de México ( México: Guarania, 1952), 212. 
En Ciudad de México, se podía comer en la calle con medio real y cenar en la Plaza Mayor "tamales y otros comistrajos" con un tlaco o cuartilla de real a fines del siglo XVIII. Y en el Baratillo (otro mercado de la ciudad) comprar por el mismo dinero, otras tantas cosas tales como atole, fruta, confituras o agua "loja" con granos de cacao". ${ }^{61}$

En los mesones situados entre Querétaro, San Juan del Río, Arroyo Zarco, San Francisco arriba de Tepejí, el fraile Ajofrín, se percató de comidas similares a las anteriormente descritas para la Ciudad de México, pero lo interesante es que advirtió que las de ese tipo, estaban destinadas a los "mozos o los gañanes de servicio", a ellos se les servía atole, pulque, tortillas y clemole, platillo preparado con maíz tostado, carne acecinada, tomate y chile ${ }^{62}$ muy similar al tremolillo, otro platillo popular descrito por el Periquillo Sarniento en su andanzas por la Ciudad de México.

Las pulquerías eran otros sitios en los que comían los trabajadores, ciertamente allí se refrescaban con pulque -bebida tradicional de origen prehispánico- en esos lugares se ofrecía por medio real un jarro de pulque de medio cuartillo $(250 \mathrm{ml})$ y el almuerzo; quizá el guiso más original allí ofrecido y que para los grupos privilegiados eran simplemente deshechos de animales, se preparaba con huesos de manitas de cordero, de manitas de toro, de manitas de puerco, de pies y alones de pollo. ${ }^{63}$

\footnotetext{
${ }^{61}$ Véase AHDF, Rastros y Mercados, Vol. 3728, exp. 13. También AGN, Archivo Histórico de Hacienda, Vol. 1152, leg. 1. AHDF, Moneda de Cobre, Vol. 3284, exp. 3.

62 Francisco de Ajofrin, Diario del viaje a la Nueva España... 137. Véase también "Libro de cocina del hermano Fray Gerónimo de San Pelayo", ABN, Fondo Reservado/Archivo Franciscano/1780.

${ }^{63}$ Véase "Real Junta de Policía, testimonio del expediente formado a pedimento de las almuercerías y pulqueras de los puestos de la Plaza Mayor", AGN, Archivo Histórico de Hacienda/ Leg. 994/ primera parte y Manuel Payno, Los bandidos de Río Frío (México: Porrúa, 2006).
} 
Con el propósito de caracterizar e identificar la comida diaria de un jornalero, quizá sirva asemejarla a la ración diaria de un reo en la cárcel pública de la Ciudad de México hacia 1767: "una torta de pan de 17 onzas, una libra de vaca sazonada con chile y tomate, un jarro de atole para desayuno y frijoles para cena, y en los días de vigilia por comida". ${ }^{64}$ Se sabe que un peón de la construcción ganaba diariamente 3 reales, y lograba reunir a la semana un total de 18 reales -lo que significaría que de acuerdo a los gastos del reo anteriormente mencionado- el peón podía gastar a la semana 8 reales en maíz (24 kilogramos a la semana), otros 6,1 reales en carne (1.7 kilogramos de res a la semana) y 3 y medio reales en arroz, frijoles, especies como chile y algunas hortalizas. Evidentemente para los criterios alimentarios de la época, eran raciones muy frugales e insuficientes para alimentar una familia y más ajustadas para una persona sola. Por la misma razón, en la época dentro de una familia de operarios, generalmente trabajaba el padre, la madre y los hijos, con el sencillo fin de proveerse de sus alimentos diarios. ${ }^{65}$

Por su parte, en los mesones anteriormente señalados por Ajofrín, "si se traía dinero", se podía comer algo distinto: "pan, gallinas, carnero, queso, vino, aguardiente y el puchero". Sin duda esta era la comida preferida de un gachupín o criollo, aunque el puchero, también se servía en hospitales, colegios y conventos de religiosos. El franciscano Fray Gerónimo de San Pelayo recomendaba preparar con carne de res lo que él llamó la "olla buena", algo parecido a un cocido de carne de res, con trozos de jamón, aves y

\footnotetext{
64 Archivo Histórico INAH (AHINAH), Fondo Lira, Vol. 98.

${ }^{65}$ Los maestros que trabajaban en la construcción recibían de acuerdo a su oficio un jornal diario, por ejemplo los sobrestantes estaban en el rango de 6 reales diarios, los oficiales en 5 , los peones o mano de obra no especializada en 3 reales diarios y si eran muy jóvenes "cabritos" o "medias cucharas" ganaban real y medio. También había trabajadores informales como los cargadores o los indios del mandado, que recibían como mínimo entre 3 y 4 reales por jornada o un pípila 2 reales por viaje.
} 
garbanzos y otras verduras. Platillo muy similar al puchero descrito por Manuel Payno en su novela Los Bandidos del Río Frío, aunque preparado con gallinas enteras, jamón, trozos de ternera, garbanzos y verduras. De todas formas, había diferencia entre esta comida de la meseta centronorte de México y los almuerzos típicos de las haciendas de tierra fría, donde se servía tradicionalmente carnero en mole aguado, frijoles, tortillas y jarros de tlachique. ${ }^{66}$

Una comida tan completa, como la anteriormente descrita podía costar para dos personas en las almuercerías de Ciudad de México unos cuatro reales y consistía en un par de tortas de pan con sus cubiertos, dos escudillas de caldo, dos sopas, una de fideo y otra de arroz, el puchero, dos guisados, vino, dulce y agua ${ }^{67}$ Ciertamente, no era la comida de un rico, pero tampoco estaba al alcance del presupuesto de un jornalero de la construcción como señalamos anteriormente, aunque tal vez sí, al de un oficial de albañilería o carpintería y seguramente de un maestro especializado en dichos oficios, ya que éste podía sobrepasar un jornal de seis u ocho reales diarios.

Dentro del espectro social descrito, quizá los indígenas - cuando vivían realmente apartados en el campo novohispano- fueron los únicos que conservaron una dieta más autóctona, salvo por la introducción de raciones de carne y manteca en su dieta. Harry Cross estimó que el 75\% de las necesidades energéticas de las familias campesinas durante el siglo XVIII estaban cubiertas por el consumo de maíz, y el otro $25 \%$ por frijoles, chile, manteca, porciones de carne y algunos alimentos recolectados como los quelites, las verdolagas, los nopales y algunos insectos. ${ }^{68}$ Entonces,

$\overline{66}$ Francisco Ajofrin, Diario del viaje a la Nueva España... 137. Manuel Payno, Los Bandidos de Río Frío, (México: Porrúa, 2006).

${ }^{67}$ José Joaquín Fernández de Lizardi, El Periquillo Sarmiento (México: Porrúa, 1981).

${ }_{68}$ Harry Cross, "Dieta y nutrición en el medio rural de Zacatecas y San Luis Potosí: siglos XVIII y XIX”. Revista Historia Mexicana 31: No. 1 (1990). 
no es extraño que a los indios se les viera en los campos calmar el hambre con tortillas, frijoles y chile, preparado con agua y sal, también recogían frutos de los árboles como los "mexquites" y muchos otros autóctonos. Su pobreza era grande, así como su natural desapego a lo material: "teniendo para salir del día, están contentos sin desear para mañana”. Durante sus festejos, continuaron preparando al igual que en los tiempos prehispánicos, sus tamales de chile y frutas, acompañados de pan y chocolate. ${ }^{69}$

\section{Conclusiones}

Alimentación y comida son dos términos que van de la mano en la Nueva España del siglo XVIII, especialmente porque satisfacer la necesidad física de comer implicaba para las personas utilizar un bagaje de conocimientos y tradiciones ancestrales, tanto de la cultura Prehispánica como de la Hispánica. Ambas afloraban en expresiones culinarias de compleja diversidad y combinación de alimentos que consolidaron, en ese siglo, el mestizaje alimentario. En este sentido, resulta difícil separar los ingredientes de origen indio y español, porque en las comidas tendían a ir juntos, especialmente los granos, la carne y las especias. También se integró lo dulce, lo salado, lo agrio y lo picante como nunca antes en los platillos novohispanos. Esa misma realidad, motivará que los grupos privilegiados impongan una comida con distinciones sociales muy marcadas, pero no por su procedencia étnica, sino por sus diferentes costos. Las comidas de ricos y de pobres, se reconocían por las propias autoridades encargadas de los abastos, las que debían contemplar distintas calidades de productos y diferenciar los más baratos de los caros. De ese modo, se complementaba la abundancia y la escasez, y se intentó racionalizar cada vez más las formas de comer de los pobres, con el fin de abaratar costos; así por

${ }_{69}$ Francisco Ajofrin, Diario del viaje a la Nueva España... 160. 
ejemplo se propuso aprovechar frutos autóctonos, cereales nuevos como el arroz y disfrutar del mayor rendimiento de animales como las reses. Los grupos privilegiados hicieron más aristócratas sus comidas y marcaron sus diferencias, dentro de una racionalidad perfectamente justificada por el pensamiento ilustrado.

\section{Fuentes documentales}

Alzate y Ramírez, José A. Gacetas de Literatura de México. Puebla: Manuel Buen Abad, 1831, IV Vols.

Archivo de la Biblioteca Nacional (ABN), México D.F., Fondo Reservado, Colección Archivo Franciscano.

Archivo General de la Nación (AGN), México D.F., Fondos: Alcabalas, Hospitales, Ayuntamientos, Reales Cédulas Originales.

Archivo Histórico del Distrito Federal (AHDF), México D.F., Sección Real Audiencia Fiel Ejecutoria, Fondos: Panaderías, Policía en General, Abasto de Carne, Rastros y Mercados, Archivo Histórico de Hacienda, Moneda de Cobre.

Archivo Histórico INAH (AHINAH), Fondo Lira.

Barquera, Wenceslao. Semanario Económico de México. Sobre noticias curiosas y eruditas de agricultura, medicina, minería, comercio y demás ciencias naturales, artes, oficios, literatura, etc., 1808-1810, II Vols.

Gazetas de México. Compendio de Noticias de Nueva España. México: Felipe de Zúniga y Ontiveros, 1784-1809, XV Vols.

Hernández y Maceras. El libro del arte de cozina: en el qual fe contiene el modo de guifar de comer en qualquier tiempo... Compuesto por Domingo Hernández de Maceras, cozinero en el Collegio mayor de Oviedo de la ciudad de Salamanca, 1607. 


\section{Bibliografía}

Ajofrín, Fray Francisco. Diario del viaje a la Nueva España. México: Secretaría de Educación Pública, 1986.

Barrett, Ward. "El abasto de carne en Cuernavaca durante la época colonial". En: Consumo e Historia. Una Antología. México: Instituto Mora, 2009.

Carletti, Francesco. Razonamiento de mi viaje alrededor del mundo (1594-1606). México: UNAM-Instituto de Investigaciones Bibliográficas, 1976.

Corcuera, Sonia. Entre gula y templanza. México: Universidad Nacional Autónoma de México, 1981.

Cross, Harry. "Dieta y nutrición en el medio rural de Zacatecas y San Luis Potosí: siglos XVIII y XIX". Revista Historia Mexicana 31: No. 1(1990):101-116.

Crespo, Horacio. Historia del azúcar en México. México: Azúcar, S.A./Fondo de Cultura Económica, 1990.

De Guzmán, Dominga. Recetario Mexiquense. Colección de recetarios antiguos. México: CONACULTA, 1999.

Fernández de Lizardi, José Joaquín. El Periquillo Sarniento. México: Porrúa, 1981.

Florescano, Enrique. Fuentes para la historia de la crisis agrícola de 1785-1786. México: Archivo General de la Nación, 1981.

Fonseca, Fabián de y Urrutia, Carlos de. Historia General de la Real Hacienda. México: Imprenta de Vicente García Torres, 1853.

Gage, Thomas. Nuevo reconocimiento de las Indias Orientales. México: Consejo Nacional para la Cultura y las Artes, 1994.

García, Virginia. Las panaderías, sus dueños y sus trabajadores. Ciudad de México, siglo XVIII. México: Ediciones Casa Chata No. 24, CIESAS, 1989. 
Gemelli, Giovani. Viaje a la Nueva España. México: UNAM. Dirección General de Publicaciones, 1976.

Gibson, Charles. Los aztecas bajo el dominio español. México: Siglo XXI Editores, 1967.

Hernández Jaimes, Jesús. "El fruto prohibido. El cacao de Guayaquil y el mercado novohispano, siglos XVI-XVIII". Revista Estudios de Historia Novohispana 39 (2008):43-79.

Humboldt, Alejandro. Ensayo Político sobre el reino de la Nueva España. México: Porrúa, 1978.

León García, María del Carmen. La distinción alimentaria de Toluca. México: CIESAS, 2002.

León Pinelo, Antonio. Questión moral si el chocolate quebranta el ayuno eclesiástico. Facsímil 1603. México: Conductores mexicanos. Centro de Estudios de Historia de México, 1994.

Martín Ornelas, José Manuel. "La organización económica regional y el abasto urbano: el trigo y el maíz en Zacatecas, 1749-1821". (Tesis para optar al grado de Doctor en Historia. Universidad Autónoma de Zacatecas; 2008).

Miño, Manuel. "El "cacao de Guayaquil" en Nueva España. Siglo XVIII", Revista Méxican Studies/Estudios Mexicanos 25: No. 1, (Winter 2009):1-18.

Montanari, Massimo. El hambre y la abundancia: historia y cultura de la alimentación en Europa. Barcelona: Crítica. Grupo Grijalbo, 1993.

Novo, Salvador. Cocina mexicana o historia gastronómica de la ciudad de México. México: Estudio Salvador Novo, A.C., 1993.

Ouweneel, Arij. Ciclos interrumpidos, ensayos sobre historia rural mexicana, siglos XVIII-XIX. Zinacantepec. Estado de México: El Colegio Mexiquense, 1998. 
Payno, Manuel. Los bandidos de Río Frío, México: Porrúa, 2006.

Quiroz, Enriqueta. Entre el lujo y la subsistencia. Mercado, abastecimiento y precios de la carne en la ciudad de México, 1750-1812. México: El Colegio de México/Instituto Mora, 2005.

"Del mercado a la cocina. Alimentación en la ciudad de México", en Historia de la Vida Cotidiana en México. El siglo XVIII: entre tradición y cambio, vol.III. México: Fondo de Cultura Económica/El Colegio de México, 2005, pp. 17-43.

"La moneda menuda en la circulación monetaria de la ciudad de México. Siglo XVIII". Revista Mexican Studies/Estudios Mexicanos 22: No. 2 (Summer, 2006): 219-249.

Rojas Rabiela, Teresa. La agricultura chinampera. Compilación Histórica. México: Universidad Autónoma de Chapingo, 1983.

Sedano, Francisco de. Noticias de México. Tomo I. México: Imprenta de J.R. Barbedillo, 1880.

Rozat, Guy. "Modelos para el consumo de pan en Xalapa a fines de la colonia”. En Población y Estructura Urbana en México, siglos XVIII y XIX. Xalapa: Universidad Veracruzana, 1996.

Soria, Fernando. "Ganaderos, precios y abasto de carne en Valladolid de Michoacán, 1778-1813”. (Tesis Pregrado, Universidad Michoacana de San Nicolás de Hidalgo, 2009).

Souto, Matilde, "Sobre los festines y el hambre en la Nueva España". En Gozos y sufrimientos en la historia de México. México: El Colegio de México/Instituto Mora, 2007, pp.129156.

Suárez, Clara. La política cerealera y la economía novohispana: el caso del trigo. México: Colección Miguel Othón de Mendizábal, CIESAS, 1985. 
Super, John. "Pan, alimentación y política en Querétaro en la última década del siglo XVIII". Revista Historia Mexicana 30: No.2 (1980): 248-272.

Van Young, Eric. La ciudad y el campo en el México del siglo XVIII. México. Fondo de Cultura Económica, 1989.

Valle Arizpe, Artemio. Por la vieja calzada de Tlacopan. México: Compañía General de Ediciones, 1954.

Van Bath, Slicher. Historia agraria de Europa Occidental, 5001850. Barcelona. Península, 1974.

Vargas, Elisa. Recetario novohispano: México, siglo XVIII. México: Consejo Nacional para la Cultura y las Artes, 2000.

Viera, Juan de. Compendiosa narración de la ciudad de México. México: Guarania, 1952.

Villarroel, Hipólito. Enfermedades políticas. México: Porrúa, 1979.

Viqueira, Juan Pedro. ¿Relajados o reprimidos? Diversiones públicas y vida social en la ciudad de México durante el Siglo de las Luces. México: Fondo de Cultura Económica, 1987.

Zárate, Verónica. "Los privilegios del nombre. Los nobles novohispanos a fines de la época colonial". En Historia de la Vida Cotidiana en México. El siglo XVIII: entre tradición y cambio, vol. III. México: Fondo de Cultura Económica/El Colegio de México, 2005, pp.325-356.

\section{Citar este artículo:}

Enriqueta Quiróz, "Comer en Nueva España. Privilegios y pesares de la sociedad en el siglo XVIII”, Revista Historia y Memoria No: 08, (enero-junio, 2014), pp. 19-58 